\title{
Heat-induced antigen retrieval in fluorescence in situ hybridization: An effective approach enhancing signal intensity in poor-quality FFPE sections
}

\author{
QIUXIAO YU* , CHI ZHANG* , WENTING HUANG and LI LI \\ Department of Pathology, National Cancer Center/National Clinical Research Center for \\ Cancer/Cancer Hospital and Shenzhen Hospital, Chinese Academy of Medical Sciences and \\ Peking Union Medical College, Shenzhen, Guangdong 518116, P.R. China
}

Received July 1, 2021; Accepted September 17, 2021

DOI: $10.3892 /$ etm.2021.10915

\begin{abstract}
Fluorescence in situ hybridization (FISH) serves as an ancillary tool for assessing chromosomal abnormalities and is important in differential diagnoses and treatment decisions. In clinical practice, pathologists encounter unsatisfactory formalin-fixed paraffin-embedded (FFPE) sections exhibiting weak fluorescence signals, mostly due to inappropriate tissue processing or preservation, leading to interpretation difficulties. For the present study, FFPE samples for which conventional FISH failed were collected. Instead of a pretreatment step using a commercial kit, heat-induced antigen retrieval (HIAR) was introduced using either citrate buffer or Tris-EDTA buffer, while the subsequent experimental workflow remained unchanged. After HIAR-assisted FISH, the hybridization efficiency and signal intensity were markedly enhanced and no difference in signal adequacy was observed when comparing the effect of the two AR solutions. The present study demonstrated that HIAR is a reliable tool for FISH, particularly for poor-quality FFPE sections yielding weak or no fluorescence signals in the conventional analysis.
\end{abstract}

\section{Introduction}

Fluorescence in situ hybridization (FISH) is a well-established technique in pathology laboratories for the identification of

Correspondence to: Dr Wenting Huang or Dr Li Li, Department of Pathology, National Cancer Center/National Clinical Research Center for Cancer/Cancer Hospital and Shenzhen Hospital, Chinese Academy of Medical Sciences and Peking Union Medical College, 113 Baohe Avenue, Longgang, Shenzhen, Guangdong 518116, P.R. China

E-mail: huangwt@cicams.ac.cn

E-mail: 1ilybc@163.com

${ }^{*}$ Contributed equally

Key words: fluorescence in situ hybridization, heat-induced antigen retrieval, weak fluorescence signal recurrent tumor-specific chromosomal translocations and copy number variations, assisting in clinical diagnosis and the selection of treatment strategies (1). FISH offers distinct advantages over other molecular diagnostic methods. Unlike reverse transcription-polymerase chain reaction (RT-PCR) or next-generation sequencing (NGS), FISH utilizes fluorophore-coupled probes that specifically bind to complementary sequences and provides detailed intracellular localization of target genes, which is particularly important when evaluating tissues with small tumor volumes or tumors consisting of multiple mixed cells $(2,3)$. For gene rearrangement, a FISH break-apart probe is capable of detecting all possible rearrangements involving a common breakpoint region despite corresponding fusion partners or variants. By contrast, the RT-PCR technique requires multiple pairs of primers to identify certain known rearrangements, which is time-consuming and relatively inefficient (4).

There are also limitations with FISH, which may result in experimental failure or diagnostic errors. The lack of standard interpretation guidelines for multiple FISH probes leads to difficulties in explaining atypical, abnormal signal patterns, such as isolated or unbalanced signals (5). Furthermore, it is necessary for clinical laboratories to establish an analytical normal cutoff value for individual probes, which may vary among different institutions. Another challenge for FISH detection is the sample quality, which is predominantly determined by the tissue processing procedure and tissue component. Fixation time, storage, decalcifying agents, and collagen and extracellular matrix abundance may influence the intensity of FISH signals and therefore hinder pathological diagnosis (4). In clinical practice, one obstacle for FISH is that not all pathology archives are desirable. Unsatisfactory paraffin blocks or FFPE sections always lead to interpretation failure and difficulties in clinical diagnosis. To solve this problem, conventional FISH procedures urgently require to be improved.

Heat-induced antigen retrieval (HIAR) is an effective method widely applied in immunohistochemistry to unmask antigens in FFPE sections (6). Prompted by this simple technique, the present study provided a modified FISH protocol. In the pretreatment step, HIAR with either citrate or Tris-EDTA 
buffer was applied to poor-quality FFPE sections that failed in the conventional pathology workflow, and the detection validity and signal intensity markedly improved. In addition, evaluation data acquired from two HIAR-assisted FISH methods were compared and the same interpretation results were obtained. Overall, this protocol is sufficient for enhancing FISH signals and produces reliable results.

\section{Materials and methods}

Tissue samples. Among 328 archived tumor tissues sent to the National Cancer Center/National Clinical Research Center for Cancer/Cancer Hospital and Shenzhen Hospital (Shenzhen, China) for FISH detection from January 2020 to May 2021, seven FFPE sections failed in conventional FISH experiments and HIAR-FISH was performed for these samples to assess the efficacy of the modified protocol. Furthermore, four adequately handled specimens were randomly selected to evaluate whether HIAR would affect the original signal pattern. The median age of the patients ( 9 male and 2 female) was 45 years. Our study cohort consisted of nine cases of soft tissue sarcomas and two cases of microphthalmia family translocation renal cell carcinoma. All samples were excision tissues and sectioned at $4-\mu \mathrm{m}$ thickness for detection. Patient clinical and pathological characteristics are summarized in Table I.

FISH protocol. FISH experiments were performed on the interphase nuclei of 4- $\mu \mathrm{m}$ FFPE sections using commercial probe kits, including synovial sarcoma translocation chromosome 18 (SS18), Ewing sarcoma breakpoint region 1 gene (EWSR1), DNA damage inducible transcript 3 (DDIT3), transcription factor binding to IGHM enhancer 3 (TFE3) and murine double minute-2 (MDM2). The detailed probe information is listed in Table II, and all probes were diluted 1:10 with LSI/WCP hybridization buffer (Abbott Molecular, Inc.).

Conventional FISH was performed using a Vysis paraffin pretreatment IV \& post hybridization wash buffer kit (Abbott Molecular, Inc.) following the manufacturer's protocol, as illustrated in Fig. 1. In brief, the FFPE slides were dewaxed in $100 \%$ xylene, dehydrated in $100 \%$ ethanol and dried in air. For tissue pretreatment, the slides were immersed in pretreatment solution containing $1 \mathrm{~N}$ sodium thiocyanate (NaSCN) at $80^{\circ} \mathrm{C}$ for 10-15 $\mathrm{min}$ and then soaked in purified water for $3 \mathrm{~min}$. Subsequently, the excess water along the edges of the slides was removed with a paper towel, followed by enzymatic digestion using pepsin buffer $(1.5 \mathrm{mg} / \mathrm{ml})$ for $10-15 \mathrm{~min}$ at $37^{\circ} \mathrm{C}$. The slides were then immersed in purified water for $3 \mathrm{~min}$ at room temperature. After ethanol gradient dehydration, diluted probes were applied to the target tissue areas and the slides were processed with the ThermoBrite Denaturation/Hybridization System (Abbott Molecular, Inc.) using the following program: $10 \mathrm{~min}$ at $82^{\circ} \mathrm{C}$ and $12-16 \mathrm{~h}$ at $37^{\circ} \mathrm{C}$. The next day, the slides were rapidly washed with $2 \mathrm{X}$ saline sodium citrate buffer (SSC) $/ 0.1 \%$ nonidet $\mathrm{P}$ (NP)-40 at ambient temperature for 3-5 $\mathrm{min}$ and $0.7 \mathrm{X} \mathrm{SSC} / 0.3 \% \mathrm{NP}-40$ at $74^{\circ} \mathrm{C}$ for $2 \mathrm{~min}$. After air-drying in the dark, the tissues were counterstained using DAPI to visualize nuclei. FISH signals were viewed with suitable filter sets under a fluorescence microscope (magnification, x600; Leica Microsystems $\mathrm{GmbH}$ ) and the images were captured using a Bioview Allegro Plus System (Abbott Molecular, Inc.) with the same parameter settings.

HIAR in FISH. HIAR was applied for slides exhibiting unsatisfactory signals in conventional FISH (Fig. 1). In the present study, two AR solutions of different $\mathrm{pH}$ values were used: Citrate buffer ( $\mathrm{pH}=6.0)$ and Tris-EDTA buffer $(\mathrm{pH}=9.0)$. In detail, AR solution was added into a pressure cooker on a hotplate. The lid of the cooker was simply rested on top at this point. After boiling, slides were rapidly immersed in AR solution and the cooker lid was secured. Once the cooker reached the full pressure, conditions were maintained for $2 \mathrm{~min}$. Subsequently, the pressure cooker was placed in an empty sink and the pressure valve was carefully released. Once depressurized, the lid was removed and slides were cooled at room temperature for $60 \mathrm{~min}$.

FISH signal enumeration. For each case, the slide adequacy was evaluated according to three criteria: i) The background should be dark and relatively free of fluorescence particles; ii) the fluorescence signals under both channels should appear unequivocal, bright and easily identified; and iii) the nuclei morphology should be intact and distinguishable. Only slides with these features were interpreted.

A minimum of 50 non-overlapping nuclei were counted for each case independently by two pathologists (16 and 2 years of experience, respectively) in a blinded manner. For break-apart probes targeting EWSR1, DDIT3, SS18 and TFE3, the typical rearrangement pattern was $1 \mathrm{~F} / 1 \mathrm{G} / 1 \mathrm{O}$ ( 1 fusion, 1 green, 1 orange) and the cell was considered positive when at least one set of green and orange signals were separated at $\geq 2$ signal diameters apart. Cells without rearrangement exhibited fused or adjacent (distance $<2$ signal diameters) green and orange signals. The cutoff value for each break-apart probe was $15 \%$ in our laboratory, which was established as recommended by the American College of Medical Genetics guidelines $(1,7)$. For the MDM2/CEP12 probe, amplification was considered to have occurred in cells with an MDM2 (orange)/CEP12 (green) ratio $\geq 2.0$.

Statistical analysis. To quantify the hybridization efficiency of different FISH protocols, three captured views of individual samples were randomly selected and quantification of i) the total cell number, ii) number of cells with clear fluorescence signals (either green or orange), and iii) number of cells conforming to interpretation criteria above was performed. The percentage of cells is presented as the mean \pm standard error of the mean. All analyses were performed using GraphPad Prism software 5.0 (GraphPad Software, Inc.).

\section{Results}

HIAR markedly promotes FISH efficiency in detecting fluorescence signals. In conventional FISH experiments using commercial pretreatment kits, all seven pathology samples failed to meet the interpretation standard because the density ratio of signal to background was low in either the orange or green channel, making it impossible to identify signal patterns. To obtain satisfactory results, HIAR was introduced to replace the pretreatment step. Of the seven 
Table I. Clinicopathological information of the cases.

\begin{tabular}{|c|c|c|c|c|c|}
\hline Case no. & Sex & $\begin{array}{l}\text { Age, } \\
\text { years }\end{array}$ & Site & $\begin{array}{l}\text { Specimen } \\
\text { type }\end{array}$ & Diagnosis \\
\hline 1 & $\mathrm{M}$ & 30 & Right shoulder & Excision & Clear cell sarcoma \\
\hline 2 & $\mathrm{~F}$ & 34 & Left kidney & Excision & MiT family translocation renal cell carcinoma \\
\hline 3 & $\mathrm{M}$ & 56 & Right kidney & Excision & MiT family translocation renal cell carcinoma \\
\hline 4 & $\mathrm{M}$ & 27 & Left foot & Excision & Synovial sarcoma \\
\hline 5 & $\mathrm{M}$ & 33 & Right thigh & Excision & Myxoid liposarcoma \\
\hline 6 & M & 45 & Right thigh & Excision & Myxoid liposarcoma \\
\hline 7 & M & 55 & Right thigh & Excision & Pleomorphic liposarcoma \\
\hline 8 & M & 44 & Chest wall & Excision & High-grade fibrosarcoma \\
\hline 9 & M & 54 & Retroperitoneal & Excision & Well-differentiated liposarcoma \\
\hline 10 & M & 48 & Left thigh & Excision & Low-grade fibromyxoid sarcoma \\
\hline 11 & $\mathrm{~F}$ & 53 & Abdominal wall & Excision & Undifferentiated small round cell sarcoma \\
\hline
\end{tabular}

M, male; F, female; MiT, microphthalmia.

Table II. Information on the probes.

\begin{tabular}{|c|c|c|c|c|}
\hline Probe & Type & $\begin{array}{l}\text { Chromosome } \\
\text { location }\end{array}$ & Manufacturer & Lot no. \\
\hline SS18 & Break-apart & $18 \mathrm{q} 11.2$ & Abbott Molecular, Inc. & $30-608250 / \mathrm{R} 3$ \\
\hline EWSR1 & Break-apart & $22 q 12$ & Abbott Molecular, Inc. & $30-608248 / \mathrm{R} 4$ \\
\hline DDIT3 & Break-apart & $12 q 13$ & Abbott Molecular, Inc. & $30-608246 / \mathrm{R} 3$ \\
\hline TFE3 & Break-apart & Xp11.23 & ZytoVision & Z-2109 \\
\hline MDM2/CEP12 & Amplification & $12 q 15$ & Abbott Molecular, Inc. & $30-608268 / \mathrm{R} 2$ \\
\hline
\end{tabular}

SS18, synovial sarcoma translocation chromosome 18; EWSR1, Ewing sarcoma breakpoint region 1 gene; DDIT3, DNA damage inducible transcript 3; TFE3, transcription factor binding to IGHM enhancer 3; MDM2, murine double minute-2; CEP12, chromosome enumeration probe 12 .

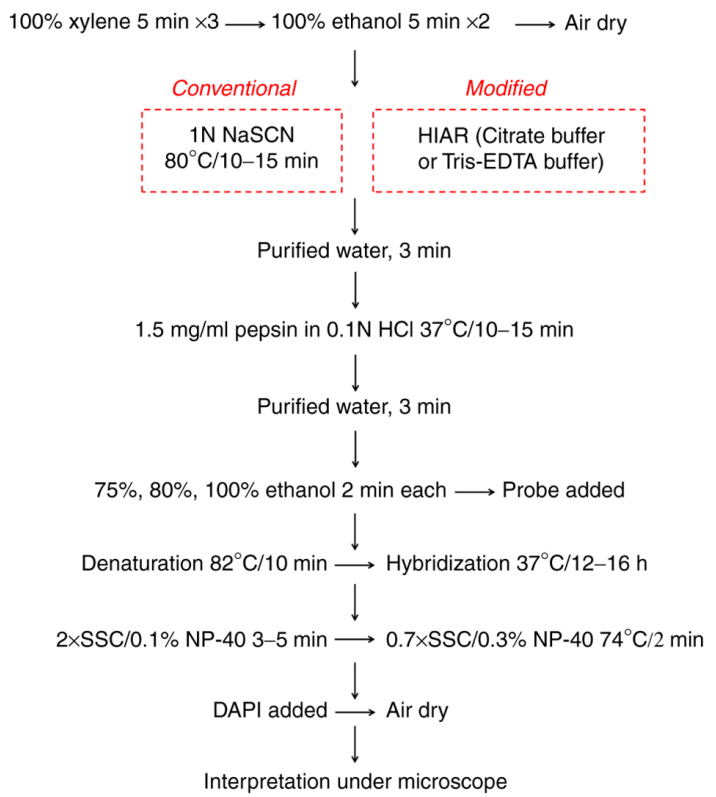

Figure 1. Flow chart of the conventional and modified fluorescence in situ hybridization protocol. HIAR, heat-induced antigen retrieval; SSC, saline sodium citrate buffer; NP, nonidet $\mathrm{P}$. samples, five were processed with both citrate buffer and Tris-EDTA buffer, while the remaining two samples were only treated with Tris-EDTA buffer due to the lack of FFPE slides provided by external medical centers. As illustrated in Fig. 2A-F, FISH analysis was successfully performed on six of the slides, which yielded clear and bright fluorescence signals in both the orange and green channels with intact cell nucleus morphology. The other sample hybridized with DDIT3 only exhibited a marginal improvement after HIAR using either HIAR buffer (data not shown). To directly illustrate the enhanced hybridization efficiency after antigen retrieval, the ratio of cells satisfying the aforementioned interpretation criteria were quantified as indicated, as well as cells exhibiting fluorescence signals, either orange or green. As depicted in Fig. 3A, only case 6 contained several interpretable cells $(<10 \%)$ after the conventional FISH experiment, but the retrieval treatment with either Tris-EDTA or citrate buffer significantly increased the ratio of non-overlapped cells clearly exhibiting both green and orange signals $(\mathrm{P}<0.001)$. Furthermore, the signal retrieval effect of the two buffers was compared and no significant difference was observed in cases 1-4. Similar results were obtained after calculating 

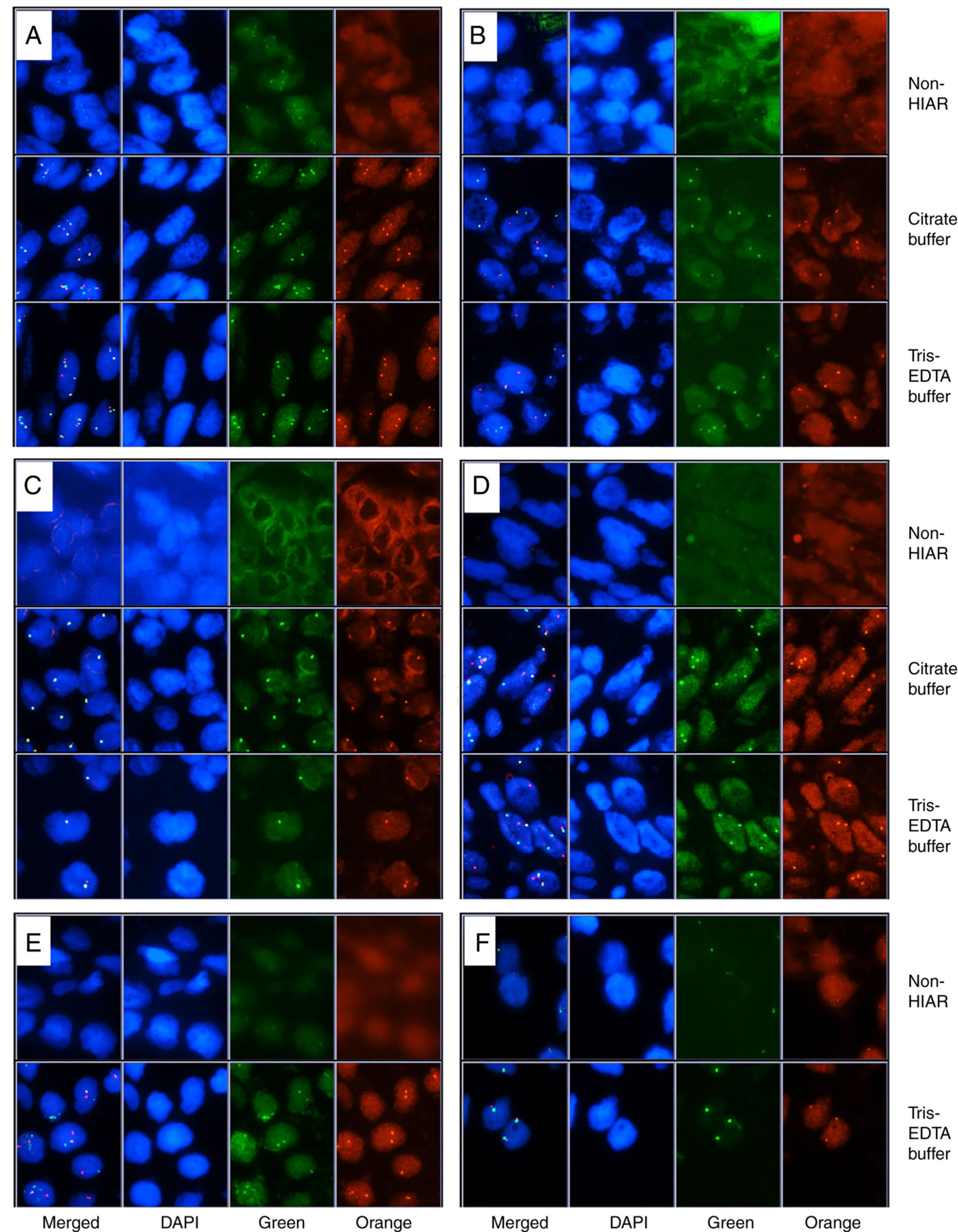

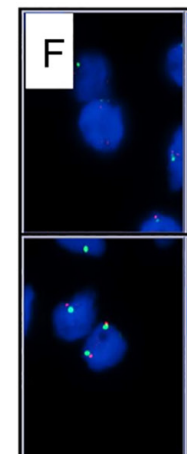

Merged

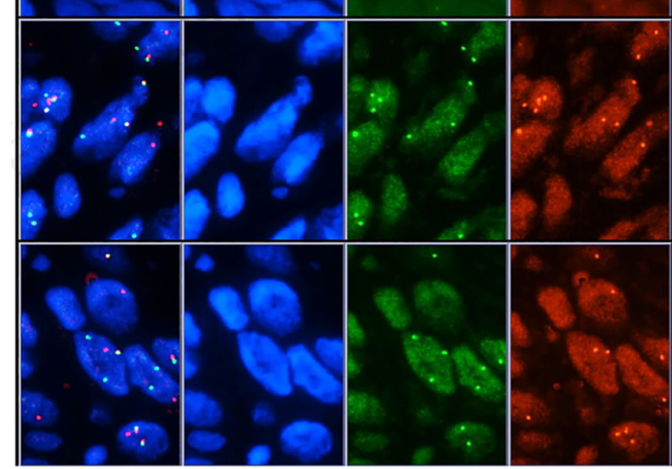

HIAR

Citrate

buffer

EDTA

buffer

Figure 2. Captured images from conventional and HIAR-assisted fluorescence in situ hybridization. Unlike slides exhibiting no signal after the routine procedure, HIAR with either citrate buffer or Tris-EDTA buffer markedly increased the fluorescence intensity. (A) Case 1/Ewing sarcoma breakpoint region 1 gene; (B) Case 2/TFE3; (C) Case 3/TFE3; (D) Case 4/synovial sarcoma translocation chromosome 18; (E) Case 5/DNA damage inducible transcript 3; (F) Case 6/murine double minute-2. Magnification, x600. HIAR, heat-induced antigen retrieval; TFE3, transcription factor binding to IGHM enhancer 3.

the percentage of cells exhibiting either a green or an orange signal (Fig. 3B). These data indicated an encouraging effect of HIAR in facilitating probe binding and fluorescence signal restoration for poor-quality FFPE slides.

Consistent interpretation results obtained with two HIAR-FISH methods. After assessing the signal quality of HIAR-FISH, two experienced pathologists interpreted the
FISH slides separately to compare the results from the two assays. The detailed counting results and final diagnosis are listed in Table III. For slides 1-4, stable results were obtained from two HIAR-FISH experiments, suggesting that these two AR solutions significantly amplified fluorescence intensity without influencing signal patterns. In addition, the interpretation results for all six samples provided by the two pathologists had high consistency. 
Table III. Fluorescence in situ hybridization interpretation results of poor-quality FFPE sections.

\begin{tabular}{|c|c|c|c|}
\hline Case/probe & $\begin{array}{l}\text { HIER } \\
\text { buffer }\end{array}$ & Pathologist 1 & Pathologist 2 \\
\hline \multirow[t]{2}{*}{ 1/EWSR1 } & Tris-EDTA buffer & $\begin{array}{l}\text { Positive } \\
(1 \mathrm{G} / 1 \mathrm{O} / 1-3 \mathrm{~F}, 30 \% ; 3-4 \mathrm{~F}, \\
52 \% \text {; other, } 18 \%)\end{array}$ & $\begin{array}{l}\text { Positive } \\
(1 \mathrm{G} / 1 \mathrm{O} / 1-3 \mathrm{~F}, 22 \% ; 3-4 \mathrm{~F}, \\
52 \% \text {; other, } 26 \%)\end{array}$ \\
\hline & Citrate buffer & $\begin{array}{l}\text { Positive } \\
(1 \mathrm{G} / 1 \mathrm{O} / 1-3 \mathrm{~F}, 28 \% ; 3-4 \mathrm{~F}, \\
\text { 44\%; other, 28\%) }\end{array}$ & $\begin{array}{l}\text { Positive } \\
(1 \mathrm{G} / 1 \mathrm{O} / 1-3 \mathrm{~F}, 30 \% ; 3-4 \mathrm{~F} \text {, } \\
40 \% \text {; other, } 30 \%)\end{array}$ \\
\hline \multirow[t]{2}{*}{ 2/TFE3 } & Tris-EDTA buffer & $\begin{array}{l}\text { Positive } \\
(1 \mathrm{G} / 1 \mathrm{O} / 1 \mathrm{~F}, 72 \% ; 2 \mathrm{~F}, \\
12 \% ; \text { other, } 16 \%)\end{array}$ & $\begin{array}{l}\text { Positive } \\
(1 \mathrm{G} / 1 \mathrm{O} / 1 \mathrm{~F}, 64 \% ; 1-2 \mathrm{~F}, \\
8 \% ; \text { other, } 28 \%)\end{array}$ \\
\hline & Citrate buffer & $\begin{array}{l}\text { Positive } \\
(1 \mathrm{G} / 1 \mathrm{O} / 1 \mathrm{~F}, 62 \%, 1 \mathrm{G} / 1 \mathrm{O}, \\
20 \% ; 1-2 \mathrm{~F}, 8 \% \text {; other, } 10 \%)\end{array}$ & $\begin{array}{l}\text { Positive } \\
(1 \mathrm{G} / 1 \mathrm{O} / 1 \mathrm{~F}, 52 \%, 1 \mathrm{G} / 1 \mathrm{O} \text {, } \\
1-2 \mathrm{~F}, 12 \% \text {; other, } 24 \%)\end{array}$ \\
\hline \multirow[t]{2}{*}{ 3/TFE3 } & Tris-EDTA buffer & $\begin{array}{l}\text { Negative } \\
(1 \mathrm{~F}, 82 \% ; 2 \mathrm{~F}, 18 \%)\end{array}$ & $\begin{array}{l}\text { Negative } \\
(1 \mathrm{~F}, 86 \% ; 2 \mathrm{~F}, 14 \%)\end{array}$ \\
\hline & Citrate buffer & $\begin{array}{l}\text { Negative } \\
(1 \mathrm{~F}, 78 \% ; 2 \mathrm{~F}, 22 \%)\end{array}$ & $\begin{array}{l}\text { Negative } \\
(1 \mathrm{~F}, 82 \% ; 2 \mathrm{~F}, 18 \%)\end{array}$ \\
\hline \multirow[t]{2}{*}{ 4/SS18 } & Tris-EDTA buffer & $\begin{array}{l}\text { Positive } \\
(1 \mathrm{G} / 1 \mathrm{O} / 1 \mathrm{~F}, 24 \% \text {; atypical } \\
\text { break-apart patterns, } 60 \% \text {; } \\
1-2 \mathrm{~F}, 16 \%)\end{array}$ & $\begin{array}{l}\text { Positive } \\
(1 \mathrm{G} / 1 \mathrm{O} / 1 \mathrm{~F}, 20 \% \text {; atypical } \\
\text { break-apart patterns, } \\
60 \% ; 1-2 \mathrm{~F}, 20 \%)\end{array}$ \\
\hline & Citrate buffer & $\begin{array}{l}\text { Positive } \\
(1 \mathrm{G} / 1 \mathrm{O} / 1 \mathrm{~F}, 20 \% \text {; atypical } \\
\text { break-apart patterns, } 58 \% \\
1-2 \mathrm{~F}, 22 \%)\end{array}$ & $\begin{array}{l}\text { Positive } \\
(1 \mathrm{G} / 1 \mathrm{O} / 1 \mathrm{~F}, 20 \% \text {; atypical } \\
\text { break-apart patterns, } 58 \% \text {; } \\
1-2 \mathrm{~F}, 22 \%)\end{array}$ \\
\hline \multirow[t]{2}{*}{ 5/DDIT3 } & Tris-EDTA buffer & $\begin{array}{l}\text { Positive } \\
(1 \mathrm{G} / 1 \mathrm{O} / 1 \mathrm{~F}, 48 \% ; 2 \mathrm{~F}, 30 \% \text {; } \\
\text { other, } 22 \%)\end{array}$ & $\begin{array}{l}\text { Positive } \\
(1 \mathrm{G} / 1 \mathrm{O} / 1 \mathrm{~F}, 44 \% ; 1-2 \mathrm{~F}, 36 \% \text {; } \\
\text { other, } 20 \%)\end{array}$ \\
\hline & Citrate buffer & N/A & N/A \\
\hline \multirow[t]{2}{*}{ 6/MDM2 } & Tris-EDTA buffer & $\begin{array}{l}\text { Negative } \\
\left(\mathrm{MDM} 2 / \text { cell, } 1.6^{\mathrm{a}} ; \mathrm{CEP} 12 /\right. \\
\text { cell, } 1.7^{\mathrm{b}} ; \mathrm{MDM} 2 / \mathrm{CEP} 12, \\
\left.0.94^{\mathrm{c}}\right)\end{array}$ & $\begin{array}{l}\text { Negative } \\
\text { (MDM2/cell, 1.66; MDM2/ } \\
\text { CEP12, 1.0) }\end{array}$ \\
\hline & Citrate buffer & N/A & $\mathrm{N} / \mathrm{A}$ \\
\hline
\end{tabular}

${ }^{a}$ The average copy number of the MDM2 gene in each tumor cell; bthe average copy number of chromosome 12 in each tumor cell; and ${ }^{c}$ the amplification ratio of the MDM2 gene in each tumor cell. N/A, not available; HIAR, heat-induced antigen retrieval; F, fusion; G, green; O, orange; EWSR1, Ewing sarcoma breakpoint region 1 gene; TFE3, transcription factor binding to IGHM enhancer 3; SS18, synovial sarcoma translocation chromosome 18; DDIT3, DNA damage inducible transcript 3; MDM2, murine double minute-2; CEP12, chromosome enumeration probe 12 .

HIAR does not affect the signal of adequately handled samples. To evaluate the effect of HIAR on well-handled samples, 4 specimens exhibiting adequate signals after conventional FISH were randomly selected and HIAR was applied to them. First, the signal intensity of these slides was compared and no significant difference was observed between conventional and HIAR-FISH using either citrate or Tris-EDTA buffer (Fig. 4A-D). The two pathologists then interpreted the FISH slides and similar results were obtained after introducing HIAR (Table IV). These data indicated that HIAR did not influence the results of FISH in adequately handled samples.

\section{Discussion}

Over the decades, precise genome testing has achieved rapid progress, demonstrating great value in definitive and differential diagnoses as well as guidance for therapy for multiple tumor types. FISH is a useful pathological tool for detecting chromosome rearrangement, amplification, gain or deletion and polysomy (8). In the present study, five specific DNA probes extensively used in pathological diagnosis were applied, including EWSR1, TFE3, SS18, DDIT3 and MDM2. Chromosomal rearrangement involving the EWSR1 (22q12) 
Table IV. Fluorescence in situ hybridization interpretation results of adequately handled samples.

\begin{tabular}{|c|c|c|c|}
\hline Case/probe & HIER buffer & Pathologist 1 & Pathologist 2 \\
\hline \multirow[t]{2}{*}{ 8/SS18 } & Tris-EDTA buffer & $\begin{array}{l}\text { Negative } \\
(2 \mathrm{~F}, 78 \% ; 3 \mathrm{~F}, 8 \% \text {; other, } 14 \%)\end{array}$ & $\begin{array}{l}\text { Negative } \\
(2 \mathrm{~F}, 80 \% ; 3 \mathrm{~F}, 10 \% \text {; other, } 10 \%)\end{array}$ \\
\hline & Citrate buffer & $\begin{array}{l}\text { Negative } \\
(2 \mathrm{~F}, 80 \% ; 3 \mathrm{~F}, 8 \% \text {; other, } 12 \%)\end{array}$ & $\begin{array}{l}\text { Negative } \\
(2 \mathrm{~F}, 76 \% ; 3 \mathrm{~F}, 12 \% ; \text { other, } 12 \%)\end{array}$ \\
\hline \multirow[t]{2}{*}{ 9/MDM2 } & Tris-EDTA buffer & $\begin{array}{l}\text { Positive } \\
\left(\text { MDM2/cell, } 21.8^{\mathrm{a}} ; \text { CEP12/ cell, }\right. \\
\left.2.2^{\mathrm{b}} ; \mathrm{MDM} 2 / \mathrm{CEP} 12,9.91^{\mathrm{c}}\right)\end{array}$ & $\begin{array}{l}\text { Positive } \\
\text { (MDM2/cell, 23.3; CEP12/cell, } \\
\text { 2.4; MDM2/CEP12,9.71) }\end{array}$ \\
\hline & Citrate buffer & $\begin{array}{l}\text { Positive } \\
\text { (MDM2/cell, 22.6; CEP12/cell, } \\
\text { 2.5; MDM2/CEP12, 9.04) }\end{array}$ & $\begin{array}{l}\text { Positive } \\
\text { (MDM2/cell, 22.9; CEP12/cell, } \\
\text { 1.9; MDM2/CEP12, 12.05) }\end{array}$ \\
\hline \multirow[t]{2}{*}{ 10/DDIT3 } & Tris-EDTA buffer & $\begin{array}{l}\text { Negative } \\
(2 \mathrm{~F}, 64 \% ; 3 \mathrm{~F}, 10 \% ; 1 \mathrm{~F}, 10 \% \text {; } \\
\text { other, } 16 \%)\end{array}$ & $\begin{array}{l}\text { Negative } \\
(2 \mathrm{~F}, 68 \% ; 3 \mathrm{~F}, 10 \% ; 1 \mathrm{~F}, 12 \% ; \\
\text { other, } 10 \%)\end{array}$ \\
\hline & Citrate buffer & $\begin{array}{l}\text { Negative } \\
(2 \mathrm{~F}, 55 \% ; 3 \mathrm{~F}, 16 \% ; 1 \mathrm{~F}, 12 \% \text {; } \\
\text { other, } 17 \%)\end{array}$ & $\begin{array}{l}\text { Negative } \\
(2 \mathrm{~F}, 63 \% ; 3 \mathrm{~F}, 12 \% ; 1 \mathrm{~F}, 8 \% \\
\text { other, } 17 \%)\end{array}$ \\
\hline \multirow[t]{2}{*}{ 11/EWSR1 } & Tris-EDTA buffer & $\begin{array}{l}\text { Negative } \\
(2 \mathrm{~F}, 80 \% ; 1 \mathrm{~F}, 12 \% ; 1 \mathrm{G} / 1 \mathrm{O} / 1 \mathrm{~F}, 2 \% \text {; } \\
\text { other, } 6 \%)\end{array}$ & $\begin{array}{l}\text { Negative } \\
(2 \mathrm{~F}, 75 \% ; 1 \mathrm{~F}, 14 \% ; 1 \mathrm{G} / 1 \mathrm{O} / 1 \mathrm{~F}, 3 \% \text {; } \\
\text { other, } 8 \%)\end{array}$ \\
\hline & Citrate buffer & $\begin{array}{l}\text { Negative } \\
(2 \mathrm{~F}, 79 \% ; 1 \mathrm{~F}, 8 \% ; 1 \mathrm{G} / 1 \mathrm{O} / 1 \mathrm{~F}, 3 \% \\
\text { other, } 10 \%)\end{array}$ & $\begin{array}{l}\text { Negative } \\
(2 \mathrm{~F}, 78 \% ; 1 \mathrm{~F}, 15 \% ; 1 \mathrm{G} / 1 \mathrm{O} / 1 \mathrm{~F}, 2 \% \text {; } \\
\text { other, } 5 \%)\end{array}$ \\
\hline
\end{tabular}

${ }^{a}$ The average copy number of the MDM2 gene in each tumor cell; ${ }^{b}$ the average copy number of chromosome 12 in each tumor cell; and ${ }^{\mathrm{c}}$ the amplification ratio of the MDM2 gene in each tumor cell. HIAR, heat-induced antigen retrieval; F, fusion; G, green; O, orange; SS18, synovial sarcoma translocation chromosome 18; MDM2, murine double minute-2; CEP12, chromosome enumeration probe 12; DDIT3, DNA damage inducible transcript 3; EWSR1, Ewing sarcoma breakpoint region 1 gene.

A

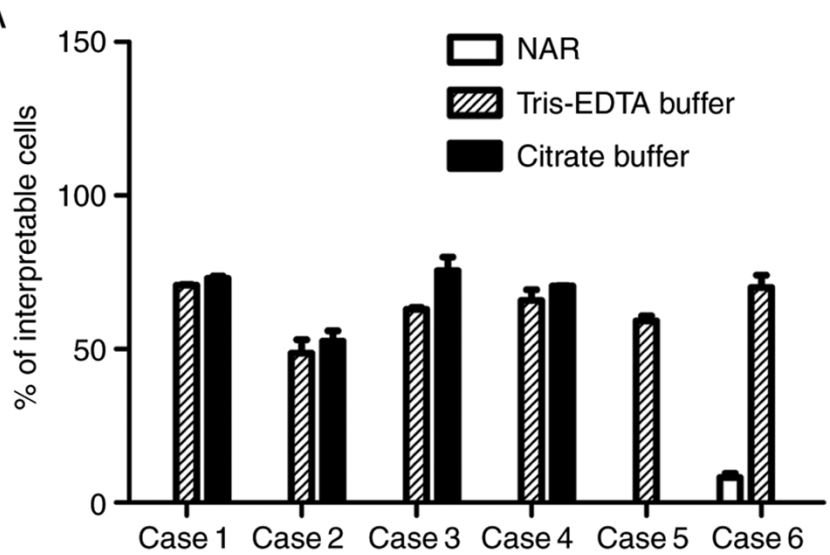

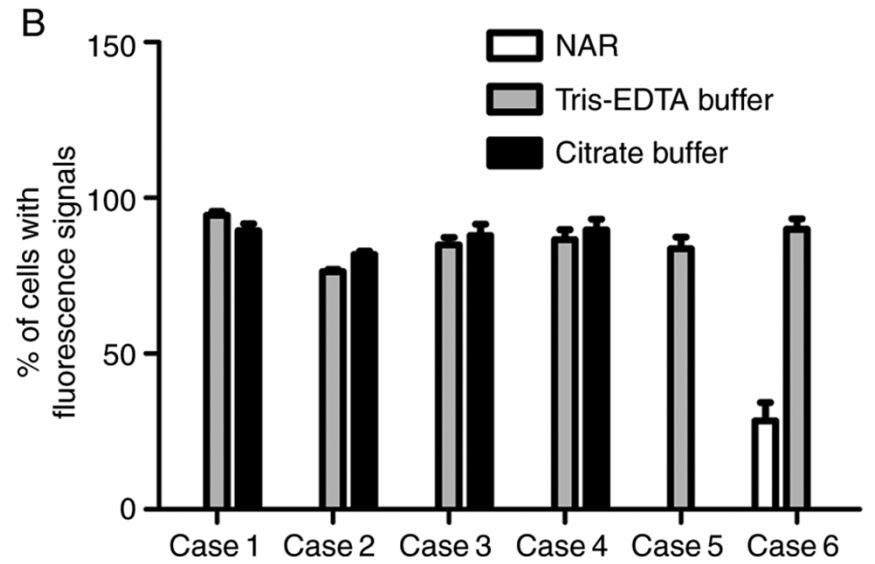

Figure 3. Statistical analysis of cells harboring fluorescence signals in different cases. Heat-induced antigen retrieval significantly enhanced the hybridization efficiency in all six cases. (A) The percentage of cells conforming to interpretation criteria and exhibiting clear fluorescence signals in both the green and orange channel. (B) The percentage of cells exhibiting clear fluorescence signals, either in the green or orange channel. NAR, no antigen retrieval.

prevalently occurs in Ewing sarcoma, and EWSR1 mostly fuses with FLI1 (11q24) and ERG (21q22) (9). Chromosomal translocation of TFE3 (Xp11.2) is an important characteristic of alveolar soft part sarcoma and microphthalmia transcription factor family translocation renal cell carcinoma $(4,10)$. Recurrent DDIT3 (12q13) rearrangement is commonly regarded as a diagnostic marker for myxoid liposarcoma with high specificity and sensitivity (11). SS18 (18q11) rearrangement occurs in $90 \%$ of synovial sarcomas but has not yet been detected in other sarcomas (12). MDM2 gene amplification is an important index for classifying atypical lipomatous tumor/well-differentiated liposarcoma and the 

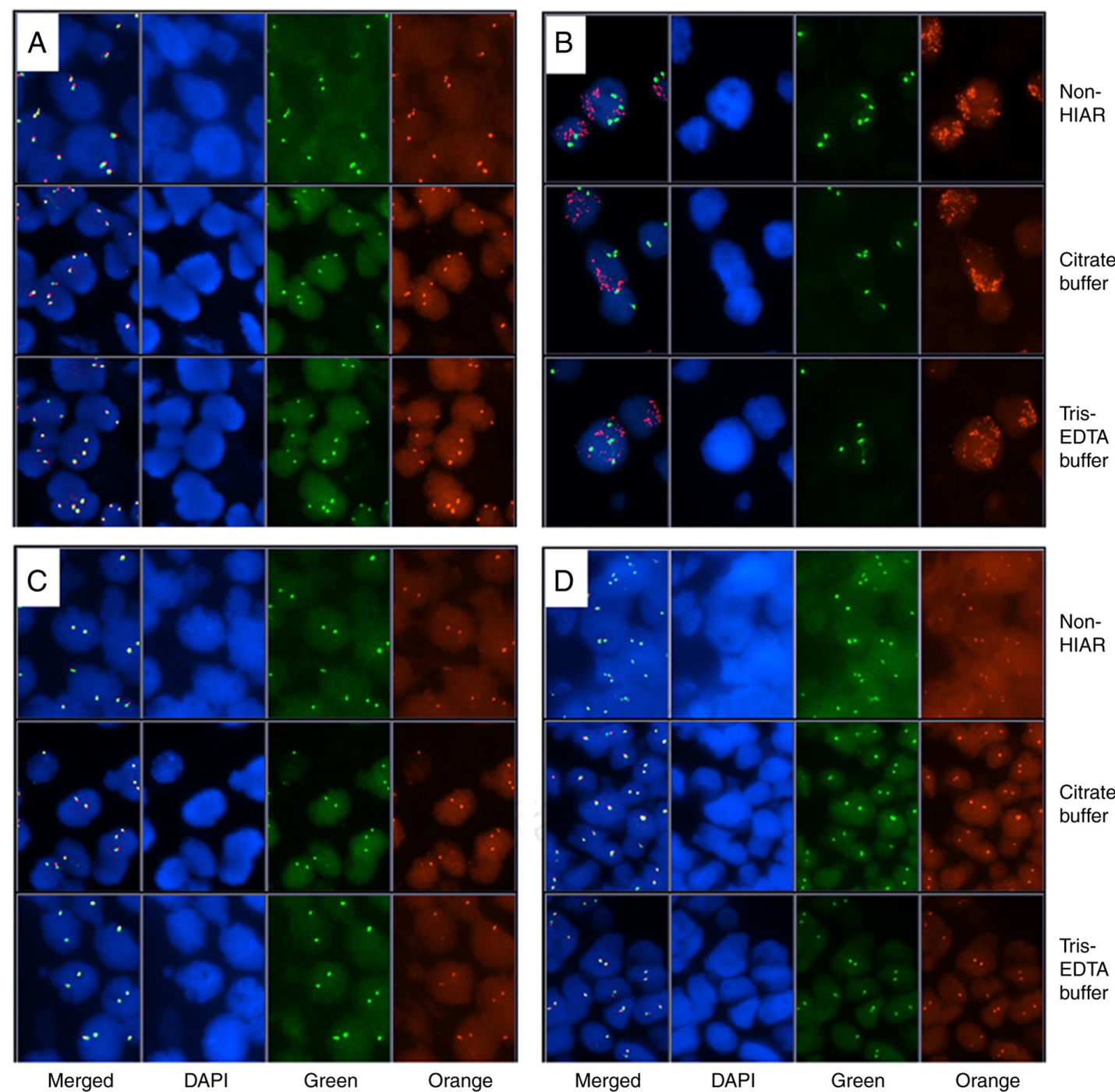

Figure 4. Captured images from conventional and HIAR-assisted fluorescence in situ hybridization. In adequately handled samples, HIAR did not affect the fluorescence signal intensity in any channel. (A) Case 8/synovial sarcoma translocation chromosome 18; (B) Case 9/murine double minute-2; (C) Case 10/DNA damage inducible transcript 3; (D) Case 11/Ewing sarcoma breakpoint region 1 gene. Magnification, x600. HIAR, heat-induced antigen retrieval.

amplification level may influence tumor dedifferentiation and progression $(13,14)$.

In laboratory practice, successful FISH detection first requires appropriate sample handling, including fixation, embedding and preservation. Poorly processed FFPE sections frequently fail with regard to signal observation and clinical diagnosis. During tissue fixation, formaldehyde produces inter- and intra-molecular crosslinks in proteins and nucleic acids. Methylene bridges are assumed to be the major structure of those crosslinks and are stable between molecules (15). Inappropriate fixation procedures, such as over-fixation, lead to excessive formation of methylene bridges and a large proportion of nucleic acids may be trapped in protein-protein crosslinks, hampering probe binding to targeted DNA sequences (16). Several troubleshooting tips have been proposed to solve this problem. One recommended method is adjusting the pretreatment and/or digestion time. Conventionally, NaSCN and pepsin are used as pretreatment and digestion reagents, respectively, to cleave crosslinks and increase tissue permeability. In the present study, slides were routinely immersed in NaSCN at $80^{\circ} \mathrm{C}$ for $10-15 \mathrm{~min}$ and subsequently, tissues were digested with pepsin at $37^{\circ} \mathrm{C}$ for $10-15 \mathrm{~min}$. To obtain clear fluorescence signals in the present study, the pretreatment and digestion time was first prolonged in increments of 3-5 min. However, extending the pretreatment time resulted in only minor signal intensity enhancement and long-term (20-25 min) soaking in NaSCN solution always resulted in swollen nuclei, which were difficult to distinguish due to nucleus overlap, particularly in dense connective tissues. Similarly, limited improvement was observed after increasing the duration of digestion. By contrast, excessive digestion led to morphological degradation of nuclei and other strategies were required to be sought to resolve this issue.

Several studies have used a microwave oven during the DNA-DNA hybridization process. In a previous study, intermittent microwave irradiation at $42^{\circ} \mathrm{C}$ with a 3 -sec irradiation/2-sec stop cycle for $1 \mathrm{~h}$, followed by overnight incubation at $42^{\circ} \mathrm{C}$ was employed (17). According to their report, among paraffin blocks yielding no signal in regular $\mathrm{FISH},>95 \%$ produced acceptable signals following this modified protocol and scanning electron microscopy revealed a looser nuclear matrix in samples exposed to microwave radiation, suggesting 
a possible mechanism underlying the enhanced probe binding activity (17). In addition, Weise et al (18) compared several different microwave settings during probe hybridization and recommended a treatment of 4-5 times of microwave exposure within $30 \mathrm{~min}$ at $600 \mathrm{~W}$. Soriani et al (19) applied the rapid FISH approach by Weise et al (18) to detect chromosome $\mathrm{t}(15 ; 17)(\mathrm{q} 24 ; \mathrm{q} 21)$ in acute promyelocytic leukemia and obtained appreciable results.

Prompted by the marked effect of microwave-produced heat in signal retrieval during DNA hybridization, HIAR may be proposed for increasing cell permeability and therefore enhancing specific probe binding ability. It is now generally accepted that the removal of intra-molecular crosslinks depends on the total amount of heat energy applied during the retrieval process instead of the heating device utilized (20). Heating undermines the gel-like structure formed by crosslinks in proteins and nucleic acids, facilitating probe penetration into nuclei and subsequent DNA binding (21). Unlike intermittent microwave irradiation, requiring multiple manual operations and careful temperature monitoring, the present method is relatively easy to follow since HIAR is already widely utilized in immunohistochemistry.

The present study has potential limitations. Up to now, only seven samples for which conventional FISH failed were collected and modified FISH was performed on them. Furthermore, due to the limited number of FFPE slides that were provided for each patient, only one necessary probe was applied to each specimen to guarantee the pathological diagnosis and comparison of signal retrieval efficiency between HIAR- and microwave-assisted FISH was not possible. For cases exhibiting atypical signal patterns, gene rearrangement cannot be validated using other methods, such as RT-PCR or NGS, as no extra sections were available for further assessment. These limitations may be addressed in future research after establishing a larger cohort. However, the current data are encouraging for the use of HIAR in FISH to enhance signal intensity, particularly for challenging specimens in clinical practice.

In summary, HIAR, which has been applied routinely in our laboratory for tumor tissues yielding weak or no signal after a standard FISH workflow, is a reliable tool in clinical FISH detection with high performance in augmenting fluorescence signals.

\section{Acknowledgements}

Not applicable.

\section{Funding}

This study was supported by the National Natural Science Foundation of China (grant no. 82002829) and the Sanming Project of Medicine in Shenzhen (grant no. SZSM201812076).

\section{Availability of data and materials}

The datasets used and/or analyzed during the current study are available from the corresponding author on reasonable request.

\section{Authors' contributions}

QY, CZ, WH and LL conceived the study. QY and CZ conducted the experiments and interpreted the results. QY performed the literature search, analyzed the data and drafted the manuscript. WH and LL revised the work for important intellectual content. WH and LL confirm the authenticity of all the raw data. All authors have read and approved the final manuscript.

\section{Ethics approval and consent to participate}

The present study was approved by the Medical Ethics Committee of the National Cancer Center/National Clinical Research Center for Cancer/Cancer Hospital \& Shenzhen Hospital, Chinese Academy of Medical Sciences and Peking Union Medical College (Shenzhen, China; approval no. 2019-39-2). Written informed consent was obtained from each patient included in this study.

\section{Patient consent for publication}

Not applicable.

\section{Competing interests}

The authors declare that they have no competing interests.

\section{References}

1. Gu J, Smith JL and Dowling PK: Fluorescence in situ hybridization probe validation for clinical use. Methods Mol Biol 1541: 101-118, 2017.

2. Tanas MR, Rubin BP, Tubbs RR, Billings SD, Downs-Kelly E and Goldblum JR: Utilization of fluorescence in situ hybridization in the diagnosis of 230 mesenchymal neoplasms: An institutional experience. Arch Pathol Lab Med 134: 1797-1803, 2010.

3. Sirvent N, Coindre JM, Maire G, Hostein I, Keslair F, Guillou L, Ranchere-Vince D, Terrier P and Pedeutour F: Detection of MDM2-CDK4 amplification by fluorescence in situ hybridization in 200 paraffin-embedded tumor samples: Utility in diagnosing adipocytic lesions and comparison with immunohistochemistry and real-time PCR. Am J Surg Pathol 31: 1476-1489, 2007.

4. Vargas AC, Selinger C, Satgunaseelan L, Cooper WA, Gupta R, Stalley P, Brown W, Soper J, Schatz J, Boyle R, et al: FISH analysis of selected soft tissue tumors: Diagnostic experience in a tertiary center. Asia Pac J Clin Oncol 15: 38-47, 2019.

5. Papp G, Mihály D and Sápi Z: Unusual signal patterns of break-apart FISH probes used in the diagnosis of soft tissue sarcomas. Pathol Oncol Res 23: 863-871, 2017.

6. Magaki S, Hojat SA, Wei B, So A and Yong WH: An introduction to the performance of immunohistochemistry. Methods Mol Biol 1897: 289-298, 2019.

7. Mascarello JT, Hirsch B, Kearney HM, Ketterling RP, Olson SB, Quigley DI, Rao KW, Tepperberg JH, Tsuchiya KD and Wiktor AE; Working Group of the American College of Medical Genetics Laboratory Quality Assurance Committee: Section E9 of the American college of medical genetics technical standards and guidelines: Fluorescence in situ hybridization. Genet Med 13: 667-675, 2011.

8. Bertram S and Schildhaus HU: Fluorescence in situ hybridization for the diagnosis of soft-tissue and bone tumors. Pathologe 41: 589-605, 2020 (In German).

9. Grünewald TGP, Cidre-Aranaz F, Surdez D, Tomazou EM, de Álava E, Kovsar H, Sorensen PH, Delattre O and Dirksen U: Ewing sarcoma. Nat Rev Dis Primers 4: 5, 2018.

10. Wyvekens N, Rechsteiner M, Fritz C, Wagner U, Tchinda J, Wenzel C, Kuithan F, Horn LC and Moch H: Histological and molecular characterization of TFEB-rearranged renal cell carcinomas. Virchows Arch 474: 625-631, 2019. 
11. Cheng L, Zhang S, Wang L, MacLennan GT and Davidson DD Fluorescence in situ hybridization in surgical pathology: principles and applications. J Pathol Clin Res 3: 73-99, 2017.

12. Stacchiotti S and Van Tine BA: Synovial sarcoma: Current concepts and future perspectives. J Clin Oncol 36: 180-187, 2018

13. Ware PL, Snow AN, Gvalani M, Pettenati MJ and Qasem SA MDM2 copy numbers in well-differentiated and dedifferentiated liposarcoma: Characterizing progression to high-grade tumors. Am J Clin Pathol 141: 334-341, 2014.

14. Miura Y, Keira Y, Ogino J, Nakanishi K, Noguchi H, Inoue T and Hasegawa T: Detection of specific genetic abnormalities by fluorescence in situ hybridization in soft tissue tumors. Pathol Int 62: 16-27, 2012.

15. Shi SR, Shi Y, Taylor CR and Gu J: New dimensions of antigen retrieval technique: 28 Years of development, practice, and expansion. Appl Immunohistochem Mol Morphol 27: 715-721, 2019.

16. Yamashita S and Katsumata O: Heat-induced antigen retrieval in immunohistochemistry: Mechanisms and applications. Methods Mol Biol 1560: 147-161, 2017.

17. Sugimura H: Detection of chromosome changes in pathology archives: An application of microwave-assisted fluorescence in situ hybridization to human carcinogenesis studies. Carcinogenesis 29: 681-687, 2008.
18. Weise A, Liehr T, Claussen U and Halbhuber KJ: Increased efficiency of fluorescence in situ hybridization (FISH) using the microwave. J Histochem Cytochem 53: 1301-1303, 2005.

19. Soriani S, Mura C, Panico AR, Scarpa AM, Recchimuzzo P, Dadati R, Farioli R, De Canal G, Mura MA and Cesana C: Rapid detection of $\mathrm{t}(15 ; 17)(\mathrm{q} 24 ; \mathrm{q} 21)$ in acute promyelocytic leukaemia by microwave-assisted fluorescence in situ hybridization. Hematol Oncol 35: 94-100, 2017.

20. Yamashita S: Heat-induced antigen retrieval: Mechanisms and application to histochemistry. Prog Histochem Cytochem 41: 141-200, 2007.

21. Stumptner C, Pabst D, Loibner M, Viertler C and Zatloukal K: The impact of crosslinking and non-crosslinking fixatives on antigen retrieval and immunohistochemistry. $\mathrm{N}$ Biotechnol 52: 69-83, 2019.

This work is licensed under a Creative Commons Attribution-NonCommercial-NoDerivatives 4.0 International (CC BY-NC-ND 4.0) License. 